\title{
Left Ventricular Systolic Dysfunction, CTCAE 5.0
}

National Cancer Institute

\section{Source}

National Cancer Institute. Left Ventricular Systolic Dysfunction, CT CAE 5.0. NCI

Thesaurus. Code C146719.

A disorder characterized by failure of the left ventricle to produce adequate output. 